\title{
Splenic artery aneurysm: pre-rupture diagnosis is life saving
}

\author{
Muwaffaq Mezeil Telfah
}

Department of Surgery, College of Medicine, University of Mosul, Mosul, Ninevah, Iraq

\section{Correspondence to} Dr Muwaffaq Mezeil Telfah, muwaffaqtelfah@yahoo.com

Accepted 10 November 2014

\section{DESCRIPTION}

A 55-year-old woman presented to the outpatient surgical clinic with a history of recurrent attacks of left upper quadrant pain over the last year. Each bout of pain lasted for less than $24 \mathrm{~h}$ and was stabbing in nature. The pain interfered with the patient's breathing and affected her left shoulder; it was associated with nausea and, occasionally, vomiting. The patient had a normal appetite, no weight loss and no change in bowel habits. She had received several courses of analgesics and antispasmodics on an assumption of left renal colic and irritable bowel syndrome. She was otherwise healthy with no relevant medical or surgical history. She neither smokes nor consumes alcohol.

During the latest attack, the patient developed severe, persistent, mainly upper abdominal pain that referred to the left shoulder, and required hospital admission in the surgical unit for further assessment. On examination, she was pale and overweight (body mass index=29.4). Her pulse was $100 / \mathrm{min}$, regular and of good volume. Blood pressure was $140 / 70 \mathrm{~mm} \mathrm{Hg}$, temperature $37.2^{\circ} \mathrm{C}$ and respiratory rate 24 breaths $/ \mathrm{min}$. Abdominal examination revealed tenderness, guarding and rigidity over the upper abdomen and mainly on the left upper quadrant. There were no palpable masses or organomegaly.

A full blood count showed haemoglobin level of $13.1 \mathrm{~g} / \mathrm{dL}$, white cell count $11 \times 10^{9} / \mathrm{L}$, platelets $250 \times 10^{9} / \mathrm{L}$ and the erythrocyte sedimentation rate was $10 \mathrm{~mm} / \mathrm{h}$. General urine examination and serum amylase level were normal. All other laboratory tests were within the normal range. Chest $\mathrm{X}$-ray in erect position showed normal lung fields and no air under the diaphragm. Ultrasound scan showed an ill-defined cystic mass (low echo-texture) at the splenorenal area suggesting a complex cystic mass related to the tail of the pancreas. Contrast-enhanced CT revealed a well-defined oval lesion $(41 \mathrm{~mm} \times 60 \mathrm{~mm})$ seen at the splenic hilum massively enhancing postcontrast, suggestive of aneurysmal dilation of splenic artery with very thin wall (figure 1). CT angiography confirmed the diagnosis of aneurysm at the distal end of the splenic artery with no thrombus within, and a dilated tortuous splenic artery (figure 2). We were concerned that this might be a case of splenic artery aneurysm (SAA) with impending rupture, which usually explains the clinical presentation of abdominal pain. Informed consent was taken and urgent surgery performed.

Laparotomy using an upper abdominal midline incision was performed. There was a tortuous course of splenic artery that ended with a thrilled, fragile, compressible mass at the hilum of spleen with a very thin wall (impending rupture), as shown in figure 3. Proximal vascular control using an arterial clamp (bulldog) was applied at the upper border of the pancreas for secure mobilisation of the spleen and to avoid catastrophic haemorrhaging. A splenectomy was performed together with excision of aneurysmal sac (figure 4). The patient had an uneventful postoperative course and was discharged on the sixth postoperative day. The patient was pain free at regular follow-up.

SAA is a rare and life-threatening condition as it has a definite risk of rupture, especially if it has a diameter of more than $2 \mathrm{~cm}^{1}{ }^{1}$ It is either symptomatic or, more commonly, asymptomatic and is therefore, in most cases, accidentally discovered during imaging. Symptoms include acute presentation with hypovolaemic shock and acute abdomen secondary to intra-abdominal haemorrhage of rupture. On the other hand, the symptoms of an unruptured aneurysm include epigastric pain, ${ }^{2}$ such as a left upper quadrant pain referring to the left shoulder, as in this case.

As seen in our case, SAA represents a diagnostic challenge clinically (misinterpreted as renal colic based on a clinical background of recurrent attacks) and also radiologically (as a cystic mass lesion related to the pancreas) with possible unfavourable consequences as a result of misdiagnosis. ${ }^{3}$ Every attempt should be made to diagnose and treat symptomatic splenic aneurysm early, before rupture, as mortality can be very high (up to $75 \%$ following rupture). ${ }^{1}$

In our case, the aneurysm was located in the distal third of the splenic artery, so the spleen could not be preserved; a splenectomy and aneurysmectomy were performed using the traditional open approach.

A number of treatment plans have been reported but open surgery is still the gold standard. ${ }^{4}$ The endovascular management is a non-invasive

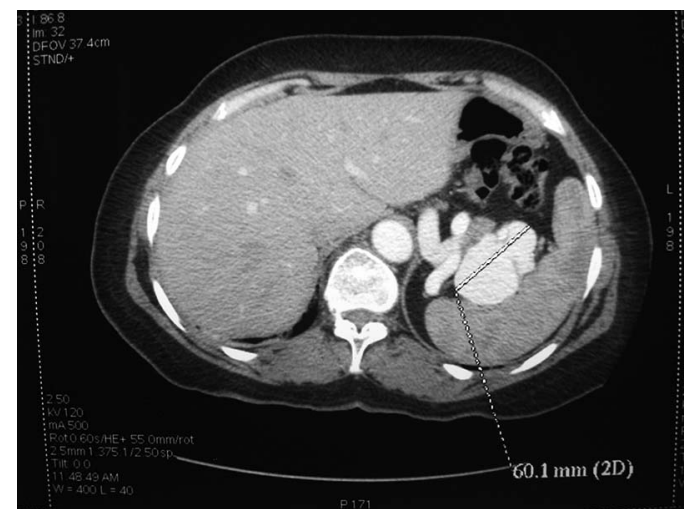

Figure 1 Contrast-enhanced CT. 
Images in...

Figure 2 CT angiogram.

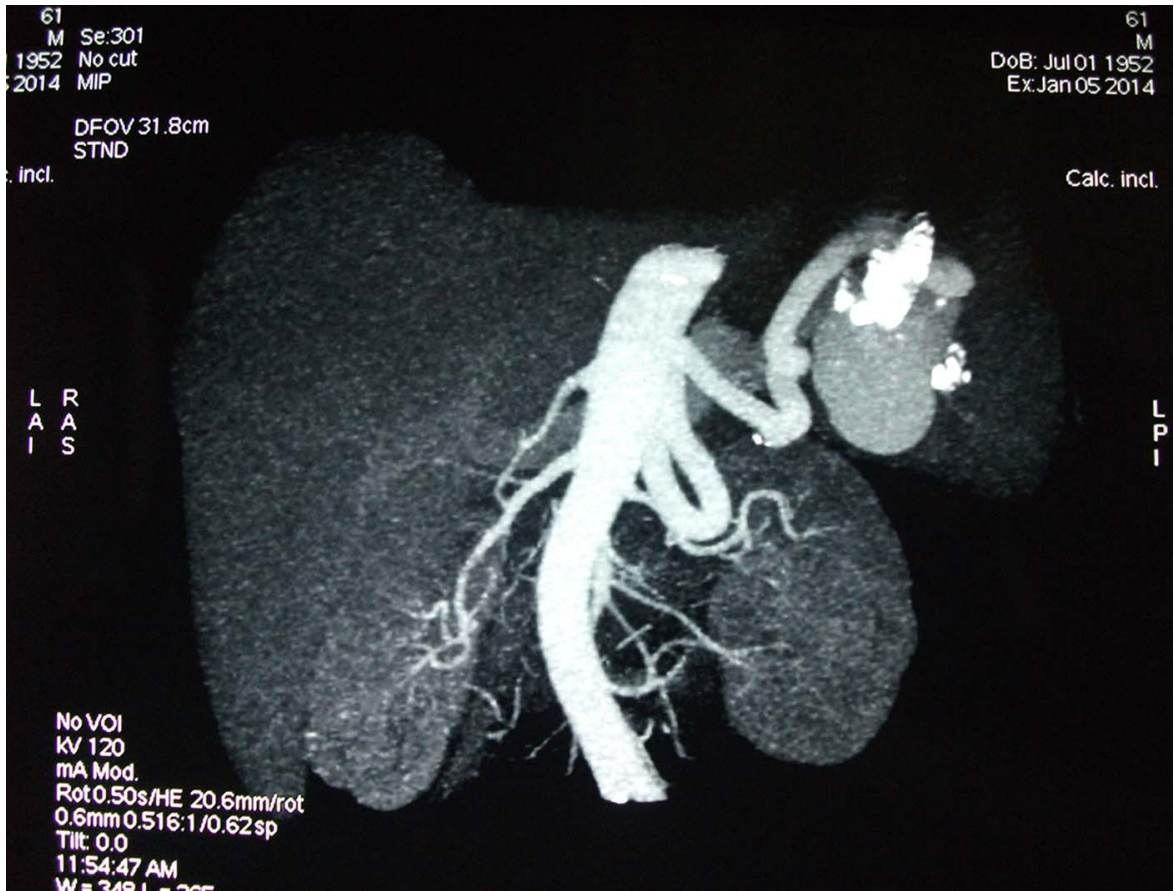

Figure 3 Operative finding of a splenic artery aneurysm within the hilum of spleen with very thin wall (impending rupture).

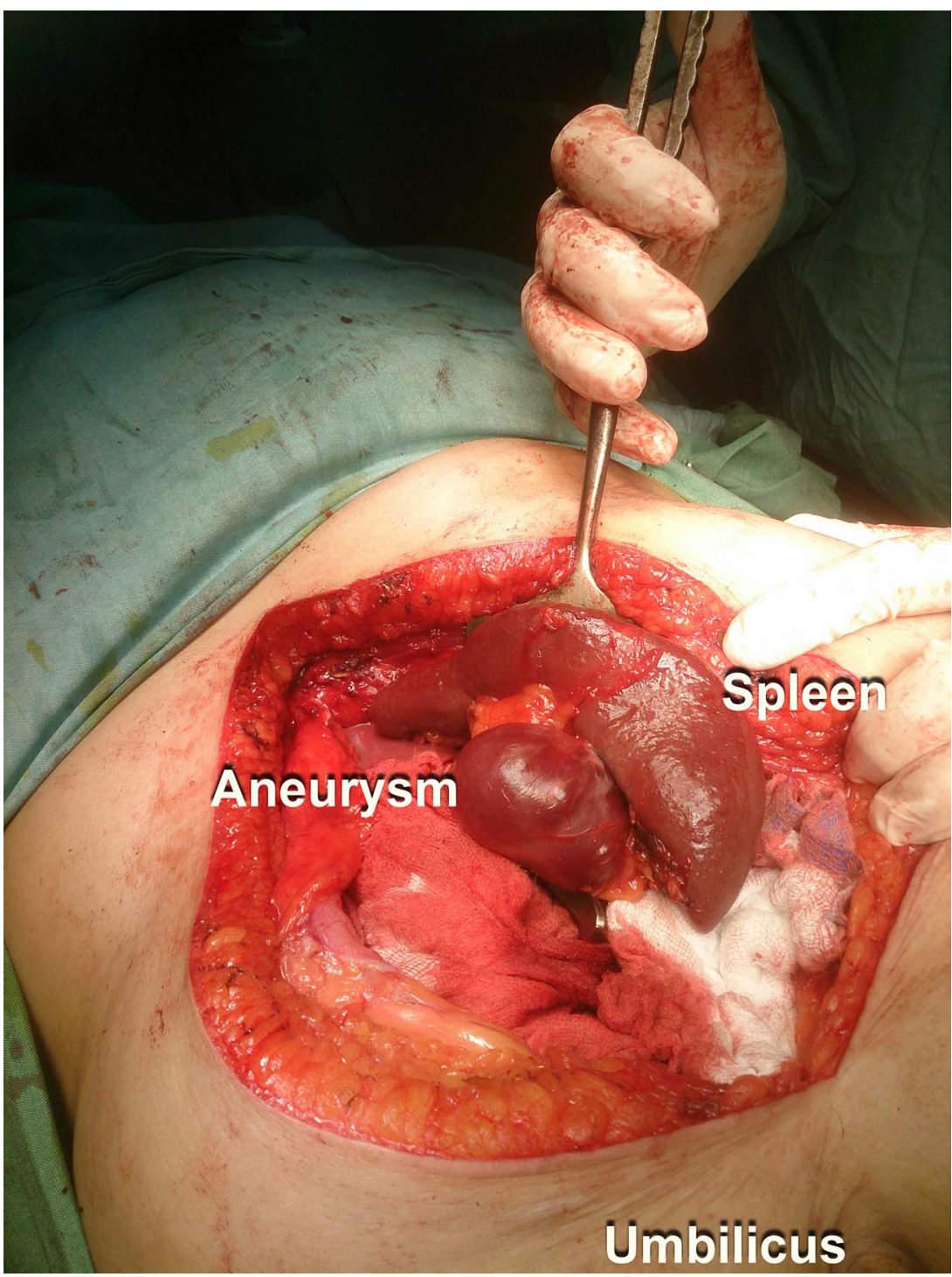


Figure 4 Splenectomy and aneurysmectomy (note the surgical tie on splenic artery proximal to the aneurysm at the tail of pancreas).

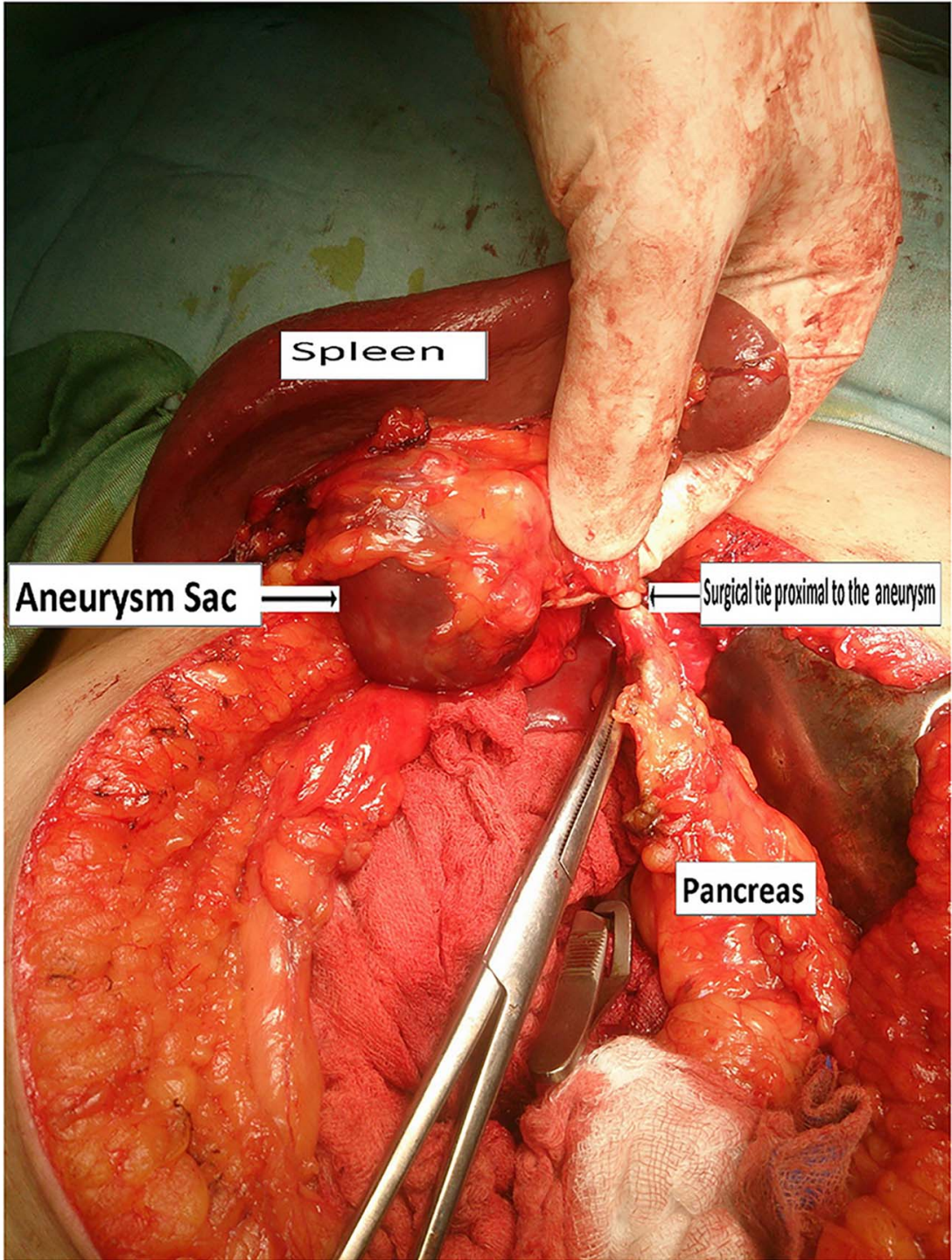

approach performed under local anaesthesia. ${ }^{5}$ However, it is only suitable for select patients. Splenic blood flow might be impaired following endovascular treatment, which could result in infarction or splenic malfunction (post-embolisation syndrome). ${ }^{6}$ Patients need careful imaging follow-up to ensure permanent exclusion of the aneurysm.

Pietrabissa et $a l^{7}$ as well as other authors, have reported the use of a laparoscopic approach for management of SAAs. Using this approach, the aneurysm can be excluded by clipping or ligation of the afferent and efferent blood vessels or excision of the aneurysmal sac without restoration of continuity of the splenic artery. The spleen will be dependent on the collateral circulation from the short gastric vessels. Sometimes a splenectomy is unavoidable due to inadequate residual blood flow to the spleen; it can be accomplished using laparoscopy without conversion. Laparoscopic management can be optimised using intraoperative coloured Doppler ultrasonography monitoring of blood flow following exclusion or ligation to avoid an unnecessary splenectomy. ${ }^{8}$ Although laparoscopic treatment is reserved for distally located aneurysms, it is difficult to manage and entails a high risk of a subsequent splenectomy.

Endovascular and laparoscopic approaches represent viable options but they require specialised equipment and expertise. However, in the absence of such facilities, equipment and skills for performing advanced treatments, and the urgency of the case reported, we found the open approach a safe and effective alternative.

A multidisciplinary approach proves very effective in offering patients optimal treatment, whether endovascular, laparoscopic or open, for visceral aneurysms.

\section{Learning points}

- A splenic artery aneurysm, although rare, should be considered in the differential diagnosis of left upper quadrant abdominal pain with referred left shoulder pain.

- Early diagnosis, using advanced imaging techniques, is crucial to prevent life-threatening rupture.

- Open splenectomy and aneurysmectomy are safe treatment options for aneurysm of the distal third of the splenic artery with impending rupture, as it is sometimes not possible to preserve the spleen.

- A number of treatment options are available for splenic artery aneurysms, such as open, laparoscopic and endovascular surgery. The local expertise, available facilities and urgency of the case will determine the safest option. 
Acknowledgements The author acknowledges all the staff members of the first surgical ward and first surgical theatre in Al Jumhoori University Hospital for their help and support. Also, special thanks to the brave anaesthetist, Dr Intisar Hamdoon, for her active support and encouragement. Equally, I appreciate the help and the care given by Dr Emad Khalil and Dr Wajida Mohamad Othman, the anaesthetists in charge of the theatre.

\section{Competing interests None.}

Patient consent Obtained.

Provenance and peer review Not commissioned; externally peer reviewed.

\section{REFERENCES}

1 Abbas MA, Stone WM, Fowl RJ, et al. Splenic artery aneurysms: two decades experience at Mayo Clinic. Ann Vasc Surg 2002;16:442-9.

2 Algudkar A. Unruptured splenic artery aneurysm presenting as epigastric pain. J R Soc Med Sh Rep 2010;1:24.
3 Casadei R, Antonacci N, Calculli L, et al. Thrombosed splenic artery aneurysm simulating a pancreatic body mass: can two entities be distinguished preoperatively thus avoiding diagnostic and therapeutic mistakes? JOP 2007;8:

235-9.

4 Yadav S, Sharma P, Singh PK, et al. Giant splenic artery aneurysm: a rare but potentially catastrophic surgical challenge. Int I Surg Case Rep 2012;3: 533-6.

5 Tulsyan N, Kashyap VS, Greenberg RK, et al. The endovascular management of visceral artery aneurysms and pseudoaneurysms. J Vasc Surg 2007;45: 276-83.

6 Piffaretti G, Tozzi M, Lomazzi C, et al. Splenic artery aneurysms: postembolization syndrome and surgical complications. Am J Surg 2007;193:166-70.

7 Pietrabissa A, Ferrari M, Berchiolli R, et al. Laparoscopic treatment of splenic artery aneurysm. J Vasc Surg 2009;50:275-9.

8 De Gaetano AM, Cotroneo AR, Maresca G, et al. Color Doppler sonography in the diagnosis and monitoring of arterial complications after liver transplantation. J Clin Ultrasound 2000;28:373-80.

Copyright 2014 BMJ Publishing Group. All rights reserved. For permission to reuse any of this content visit http://group.bmj.com/group/rights-licensing/permissions.

BMJ Case Report Fellows may re-use this article for personal use and teaching without any further permission.

Become a Fellow of BMJ Case Reports today and you can:

- Submit as many cases as you like

- Enjoy fast sympathetic peer review and rapid publication of accepted articles

- Access all the published articles

- Re-use any of the published material for personal use and teaching without further permission

For information on Institutional Fellowships contact consortiasales@bmjgroup.com

Visit casereports.bmj.com for more articles like this and to become a Fellow 